\title{
Acute hyperglycemia suppresses left ventricular diastolic function and inhibits autophagic flux in mice under prohypertrophic stimulation
}

Jiahe Xie ${ }^{1} \mathbb{0}$, Kai Cui $^{1 *}$, Huixin Hao ${ }^{1}$, Yingxue Zhang ${ }^{1}$, Hairuo Lin ${ }^{1}$, Zhenhuan Chen ${ }^{1}$, Xiaobo Huang ${ }^{1}$, Shiping Cao', Wangjun Liao², Jianping Bin ${ }^{1}$, Masafumi Kitakaze ${ }^{1,3}$ and Yulin Liao ${ }^{{ }^{*}}$

\begin{abstract}
Background: Left ventricular (LV) dysfunction is closely associated with LV hypertrophy or diabetes, as well as insufficient autophagic flux. Acute or chronic hyperglycemia is a prognostic factor for patients with myocardial infarction. However, the effect of acute hyperglycemia on LV dysfunction of the hypertrophic heart and the mechanisms involved are still unclear. This study aimed to confirm our hypothesis that either acute or chronic hyperglycemia suppresses LV diastolic function and autophagic flux.

Methods: The transverse aortic constriction (TAC) model and streptozocin-induced type 1 diabetic mellitus mice were used. LV function was evaluated with a Millar catheter. Autophagic levels and autophagic flux in the whole heart and cultured neonatal rat cardiomyocytes in response to hyperglycemia were examined by using western blotting of LC3B-II and P62. We also examined the effect of an autophagic inhibitor on LC3B-II and P62 protein expression and LC3 puncta.

Results: In mice with TAC, we detected diastolic dysfunction as early as $30 \mathrm{~min}$ after TAC. This dysfunction was indicated by a greater LV end-diastolic pressure and the exponential time constant of LV relaxation, as well as a smaller maximum descending rate of $L V$ pressure in comparison with sham group. Similar results were also obtained in mice with TAC for 2 weeks, in addition to increased insulin resistance. Acute hyperglycemic stress suppressed diastolic function in mice with myocardial hypertrophy, as evaluated by invasive LV hemodynamic monitoring. Mice with chronic hyperglycemia induced by streptozocin showed myocardial fibrosis and diastolic dysfunction. In high glucose-treated cardiomyocytes and streptozocin-treated mice, peroxisome proliferator-activated receptor- $\gamma$ coactivator 1 a was downregulated, while P62 was upregulated. Autophagic flux was also significantly inhibited in response to high glucose exposure in angiotensin-II treated cardiomyocytes.
\end{abstract}

Conclusions: Acute hyperglycemia suppresses diastolic function, damages mitochondrial energy signaling, and inhibits autophagic flux in prohypertrophic factor-stimulated cardiomyocytes.

Keywords: Acute hyperglycemia, Diastolic function, Myocardial hypertrophy, Autophagic flux

\footnotetext{
*Correspondence: cckk22@126.com; liao18@msn.com

${ }^{1}$ State Key Laboratory of Organ Failure Research, Department

of Cardiology, Nanfang Hospital, Southern Medical University, 1838

Guangzhou avenue north, Guangzhou 510515, China

Full list of author information is available at the end of the article
} 


\section{Background}

Left ventricular (LV) diastolic dysfunction is present in various cardiovascular diseases such as hypertension [1], myocardial hypertrophy [2-4], coronary heart disease [5], and diabetes mellitus (DM) [6, 7]. Worsening of diastolic dysfunction is a predictor of mortality in cardiovascular diseases and some severe non-cardiovascular diseases, including septic shock and acute pancreatitis [8-10]. The detrimental role of chronic hyperglycemia and DM on diastolic function has been well recognized [11]. The prognostic value of acute hyperglycemia in patients with acute myocardial infarction has also attracted attention of clinical investigators [12]. However, whether acute hyperglycemia is a factor that worsens diastolic dysfunction is unclear, and if so, the underlying mechanisms are unknown. Addressing these issues is of clinical importance for avoiding deterioration of diastolic dysfunction in patients with severe diseases.

Glucose deprivation causes autophagy. Therefore, hyperglycemia is likely to inhibit autophagy [13]. Insufficient autophagy is thought to cause or promote heart failure [14-16]. However, a previous report showed that increased autophagy contributes to LV diastolic dysfunction in pulmonary arterial hypertension [17]. Glucose is the main source of energy in the failing heart. Peroxisome proliferator-activated receptor- $\gamma$ coactivator (PGC)-1 $\alpha$, a transcriptional coactivator, is beneficial for heart failure by inducing a change in phenotype towards oxidative metabolism of energy [18]. The association between PGC-1 $\alpha$ and autophagy in cardiomyocytes that are exposed to high glucose is unclear. However, several lines of evidence in non-cardiomyocytes have shown that PGC- $1 \alpha$ promotes autophagy $[19,20]$. Based on all of these findings, we hypothesize that acute hyperglycemic stress suppresses diastolic function in preexistent heart disease by downregulating PGC- $1 \alpha$ and inhibiting autophagic flux.

In the present study, we investigated the effect of acute hyperglycemia on LV diastolic function in a pressureoverload model with preexistent diastolic dysfunction and insulin resistance. We also investigated the potential mechanisms related to PGC- $1 \alpha$ and autophagic flux in cultured cardiomyocytes. Although echocardiographic evaluation of LV diastolic dysfunction is a routine procedure in clinical practice, its accuracy is inferior to cardiac catheterization. Therefore, we used invasive LV hemodynamic parameters to evaluate diastolic function in this study.

\section{Methods}

TAC model

C57BL/6 male mice (9-10 weeks old) were subjected to TAC or sham operation as previously described $[2,21]$.
Briefly, prior to surgery, mice were anesthetized with a combination of ketamine $(100 \mathrm{mg} / \mathrm{kg})$ and xylazine $(5 \mathrm{mg} / \mathrm{kg}$ ) via intraperitoneal injection (ip), after intubation and artificial respiration, the chest-open was then opened via the second intercostal space to access the aorta. A non-absorbable 7-0 silk suture was tied around the aorta between the right innominate and left carotid arteries. This caused a constriction of approximately $65 \%$ using a 27 gauge-needle as a guide. For sham operations to serve as controls, mice received the same surgical procedure, except that the suture around the aorta was removed prior to closing the chest cavity. At various time points (1,2 and 4 weeks) mice were sacrificed with an overdose of pentobarbital $(150 \mathrm{mg} / \mathrm{kg})$. The hearts and lungs were dissected to measure organ weight and to perform histological analysis.

\section{Type 1 DM model}

Ten-week-old male C57BL/6 mice were purchased and injected intraperitoneally with streptozocin (STZ) (Sigma Chemicals, St. Louis, USA) $70 \mathrm{mg} / \mathrm{kg} /$ day for 5 days. STZ was dissolved in $10 \mathrm{mmol} / \mathrm{L}$ sodium citrate buffer $(\mathrm{pH}$ 4.5). Control mice were injected with the buffer alone. Three days later, mice with a random blood glucose level $>20 \mathrm{mmol} / \mathrm{L}$ were assigned to the hyperglycemic groups, whereas citrate buffer-treated mice were assigned to the control group. Six weeks later, mice were sacrificed with an overdose of pentobarbital $(150 \mathrm{mg} / \mathrm{kg})$, and the hearts were harvested for histological and molecular examinations.

\section{Invasive LV hemodynamic measurements}

Thirty minutes or 2 weeks after surgery, mice were anesthetized, intubated, and ventilated as mentioned above. A 1.4F Millar catheter (Millar Instruments, Inc., Houston, TX) was then inserted into the right carotid artery and advanced into the LV cavity. LV systolic pressure (LVSP) and LV end-diastolic pressure (LVEDP), maximum and minimum rates of change in LV pressure $(\mathrm{dp} / \mathrm{dt}$ max and $\mathrm{dp} / \mathrm{dt}$ min, respectively) were recorded. The exponential time constant of LV relaxation ( $\mathrm{\tau}$ ) was calculated using Power Lab software (blood pressure module; AD Instruments, Shanghai Trading Co, Shanghai, China). Some mice were treated with high glucose or mannitol ( $2 \mathrm{~g} /$ $\mathrm{kg}$ ip) and the time-course of LV hemodynamics was recorded. For mice that received a high glucose load test, overnight fasting was performed before the test to avoid xylazine/ketamine anesthesia-induced hyperglycemia [22].

\section{Blood glucose measurements}

Plasma glucose (fasting or in response to high glucose or insulin treatment) measurements were performed in all 
mice using a standard glucometer (Accu-Chek, Roche, Mannheim, Germany). Whole blood samples $(3 \mu \mathrm{l})$ were taken from mouse tails with a glucose sensor inserted in the glucometer. Plasma glucose concentrations were read $30 \mathrm{~s}$ later. Serum insulin levels were measured according to the protocol provided by the manufacturer (EIA-3440 enzyme linked immunosorbent assay kit; Diagnosisrelated Group, Germany). Homeostasis model assessment for insulin resistance (HOMA-IR) values were determined from results of the fasting blood glucose (FBG) and fasting insulin (FINS) tests, using the equation HOMA-IR $=[\mathrm{FBG}(\mathrm{mg} / \mathrm{dl}, 1 \mathrm{mmol} / \mathrm{L}=18 \mathrm{mg} /$ $\mathrm{dL}) \times$ FINS $(\mathrm{ng} / \mathrm{ml})] / 22.5$.

\section{Histology examination}

The extent of myocardial fibrosis was measured, as described elsewhere $[21,23]$. Hearts were fixed with $10 \%$ formalin, and each heart was cut into four sections and stained with Masson trichrome.

\section{Cell culture}

Ventricular myocytes were prepared from Sprague-Dawley rats (age, 1-2 days), which were obtained from the Animal Center of Southern Medical University. In brief, the rats were sacrificed by $2 \%$ isoflurane inhalation. The hearts were quickly excised and immediately embedded in freezing Hank's solution. Cardiomyocytes were dispersed by digestion with $0.1 \%$ trypsin and $0.03 \%$ collagenase at $37{ }^{\circ} \mathrm{C}$. The cells were then collected after differential adhesion of non-cardiomyocytes and plated at a density of 150-200 cells $/ \mathrm{mm}^{2}$. Cardiomyocytes were incubated for $48 \mathrm{~h}$ in Dulbecco's modified Eagle's medium supplemented with $10 \%$ fetal calf serum and then grown for $24 \mathrm{~h}$ under serum free conditions. Cells were treated with angiotensin II $(1 \mu \mathrm{mol} / \mathrm{L})$ and/or highglucose solution $(25 / 50 \mathrm{mmol} / \mathrm{L})$, and collected for protein extraction at $24 \mathrm{~h}$.

\section{Western blotting}

Protein was obtained from cultured cardiomyocytes or hearts from STZ-treated mice, and was extracted in radio-immunoprecipitation assay lysis buffer. Samples were loaded onto $10 \%$ sodium dodecyl sulfatepolyacrylamide gels and the protein was transferred to polyvinyl difluoride membranes. Immunoblotting was then performed by using PGC- $1 \alpha$ antibody (ab191838; Abcam, Shanghai, China) or autophagy antibodies (light chain 3 beta [LC3B]-I/II, 2775s; and P62, 5114s; Cell Signaling Technology, Danvers, MA), and GAPDH antibody (ARG10112; Arigo, Taiwan, China). Immunoreactive bands were visualized by the enhanced chemiluminescence method (Amersham, Piscataway, NJ) with a western blotting detection system (Kodak Digital Science, Rochester, NY). These bands were quantified by densitometry with Scion Image software (Image J 1.42q; $\mathrm{NIH}$, Bethesda, MD). We used the LC3B-II/loading control ratio rather than the LC3B II/LC3B-I ratio for qualification of LC3-II expression levels according to a newly published guideline [24].

\section{Assay of autophagic flux}

To measure autophagic flux, cardiomyocytes were treated with bafilomycin A1 (Selleck; Texas, USA), a lysosomal inhibitor, at $100 \mathrm{nmol} / \mathrm{L}$ for $24 \mathrm{~h}$. Cellular autophagic flux was estimated by western blots of LC3B-II and P62 protein as well as by tandem fluorescent mRFP-GFP-LC3. Cultured cardiomyocytes were infected with lentivirus carrying mRFP-GFP-LC3 (Cat. No. GPL2001; Genechem Co., Shanghai, China) for $72 \mathrm{~h}$ (multiple of infection $=25)$. subsequently, cells were either treated with angiotensin II $(1 \mu \mathrm{mol} / \mathrm{L})$, glucose $(5.5$ or $25 \mu \mathrm{mol} / \mathrm{L})$, or bafilomycin A1 (100 nmol/L) for $24 \mathrm{~h}$. Cells were then washed with PBS, fixed with $4 \%$ paraformaldehyde and viewed under confocal laser scanning microscopy (Olympus FV1000; Japan). In merged images, puncta in autophagosome appeared yellow, while puncta in autolysosomes appeared red.

\section{Statistical analysis}

All data analyses were performed using SPSS 17.0 software (SPSS, Inc., Chicago, IL). Data are presented as mean \pm standard error of the mean. Comparisons were made using unpaired Student's $t$ tests and one-way or two-way ANOVA, as appropriate. P-values less than 0.05 were considered statistically significant.

\section{Results}

\section{Diastolic dysfunction appears in the early phase} of pressure overload

In mice with TAC for $30 \mathrm{~min}$, invasive evaluation of LV hemodynamics using a Millar catheter. In comparison with sham group, LVEDP and the exponential time constant of LV relaxation ( $\tau$ ) were greater, while LV dp/ $\mathrm{dt}$ min was smaller in TAC group. These findings indicated damage of diastolic function (Fig. 1a-h).

\section{Diastolic dysfunction and insulin resistance appear in mice with cardiac hypertrophy}

In mice with TAC for 2 weeks, the diastolic parameters LVEDP and $\mathrm{\tau}$ were greater, $\mathrm{dp} / \mathrm{dt} \min$ and $\mathrm{dp} / \mathrm{dt}$ max corrected by LV systolic pressure was significantly smaller than in the sham group. These findings indicated that chronic TAC can induce diastolic and systolic dysfunction (Fig. 2a-e). Cardiac hypertrophy was identified 


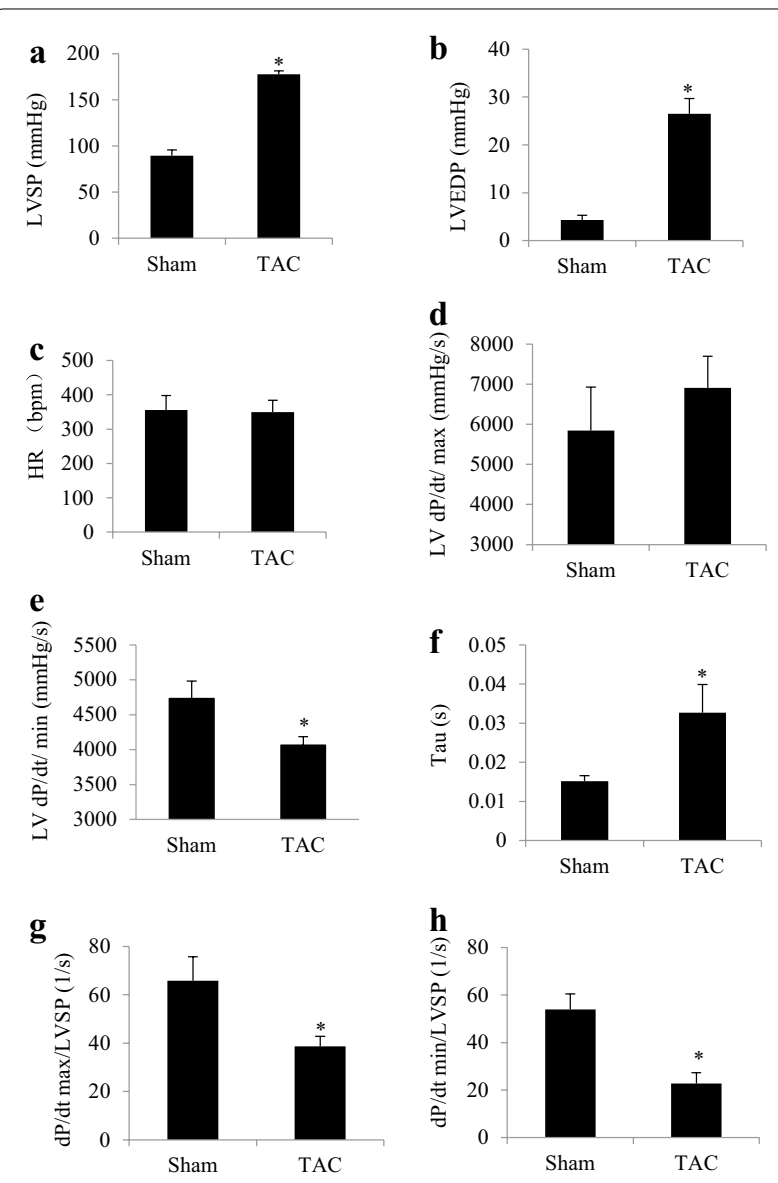

Fig. 1 Diastolic dysfunction appears in the early phase of pressure overload. After 30 min of transverse aortic constriction (TAC) in C57 mice, invasive hemodynamics were evaluated. a Left ventricular systolic pressure (LVSP). b Left ventricular end-diastolic pressure (LVEDP). c Heart rate. $\mathbf{d}$ Maximum rate of change in left ventricular pressure (dp/dt max). e Minimum rate of change in left ventricular pressure (dp/dt min). f Exponential time constant of relaxation ( $\mathrm{\tau}$ ). $\mathbf{g} \mathrm{dp} / \mathrm{dt}$ max corrected with LVSP. $\mathbf{h} \mathrm{dp} / \mathrm{dt}$ min corrected with LVSP. ${ }^{*} P<0.05$ versus the sham group, $n=6$ and 9 in the sham and TAC groups, respectively

according to a significant greater heart to body weight ratio than in the sham group (Fig. 2f). The results of an intraperitoneal glucose tolerance test showed significantly higher peak glucose levels in the TAC group than in the sham group (Fig. 3a). This finding suggested glucose tolerance in mice with cardiac hypertrophy. An insulin resistance test showed that plasma glucose concentrations at $30 \mathrm{~min}$ after insulin injection were higher in the TAC group than in the sham group (Fig. 3b). Additionally, the insulin resistance index HOMA-IR was significantly correlated with the heart to body weight ratio ( $\mathrm{r}=0.5383, P<0.01$, Fig. 3c).
Acute hyperglycemic stress suppresses diastolic function in mice with preexistent diastolic dysfunction

In mice with TAC for 2 weeks and sham-operated mice, the time course of LV hemodynamics in response to acute hyperglycemia (glucose $2 \mathrm{~g} / \mathrm{kg}$, ip) was evaluated (Fig. 4a-e). We found that corrected LV dp/dt min was significantly decreased at 30 and $40 \mathrm{~min}$ after glucose overload in TAC mice, but not in sham mice (Fig. 4e). There was no significant change in corrected $\mathrm{dp} / \mathrm{dt} \max$ in the TAC and sham groups (Fig. 4d). Injection of mannitol with the same osmolarity as high glucose in TAC mice had no significant effect on LV hemodynamics (Fig. 4a-e). Autophagic marker proteins were also examined. LC3B-II was lower and P62 was higher in the TAC group than in the sham group. A high glucose load further suppressed LC3B-II and increased P62 in TAC mice (Fig. 4f).

\section{High glucose levels downregulate PGC-1 $a$ and inhibit autophagic flux}

We then investigated potential mechanisms related to autophagy in cultured neonatal rat cardiomyocytes. In cardiomyocytes, high glucose levels $(\geq 25 \mathrm{mmol} / \mathrm{L})$ enhanced angiotensin II-stimulated cell growth (Fig. 5a), significantly downregulated PGC- $1 \alpha$ and LC3B-II, and upregulated the ubiquitin-binding autophagy receptor P62 (Fig. 5b-f). An autophagic flux assay showed that bafilomycin A1 increased LC3B-II and P62 protein levels in the presence of angiotensin II and high glucose levels (Fig. 6a, b). A tandem fluorescent mRFP-GFP-LC3 assay showed that angiotensin II and high glucose levels increased the ratio of autophagosomes to autolysosomes, which was enhanced by cotreatment with bafilomycin A1 (Fig. 6c, d). These results suggested that high glucose levels damaged mitochondrial energy metabolism and inhibited autophagic flux in the presence of the prohypertrophic factor angiotensin II.

\section{Chronic hyperglycemia induces LV diastolic dysfunction and inhibits autophagic flux}

In mice with STZ-induced chronic hyperglycemia, plasma glucose levels, myocardial fibrosis, diastolic function and autophagic flux were evaluated 6 weeks later. In STZ-treated mice, mean blood glucose levels reached as high as $23 \mathrm{mmol} / \mathrm{L}$ (Fig. 7a). Additionally, myocardial fibrosis appeared in the heart (Fig. 7b), and LV diastolic dysfunction was detected as shown by an increase in LVEDP and $\tau$ as well as a decrease in $\mathrm{dp} / \mathrm{dt}$ min (Fig. 7cf). Similar to the findings in high glucose-treated cardiomyocytes, we found that PGC-1 $\alpha$ was downregulated, while LC3B-II and P62 were upregulated in the heart of STZ-treated mice (Fig. 7g). 
$\mathbf{a}$

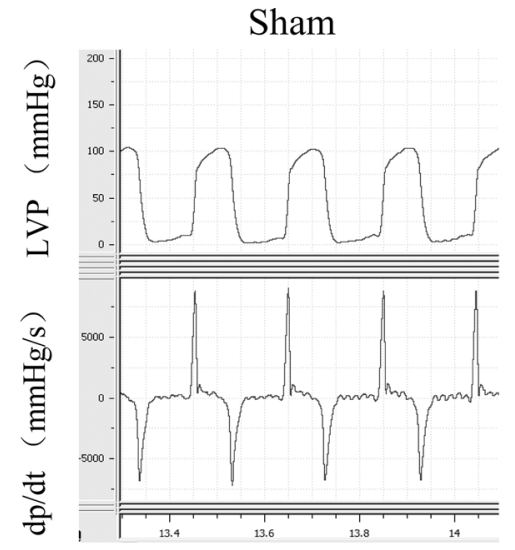

b
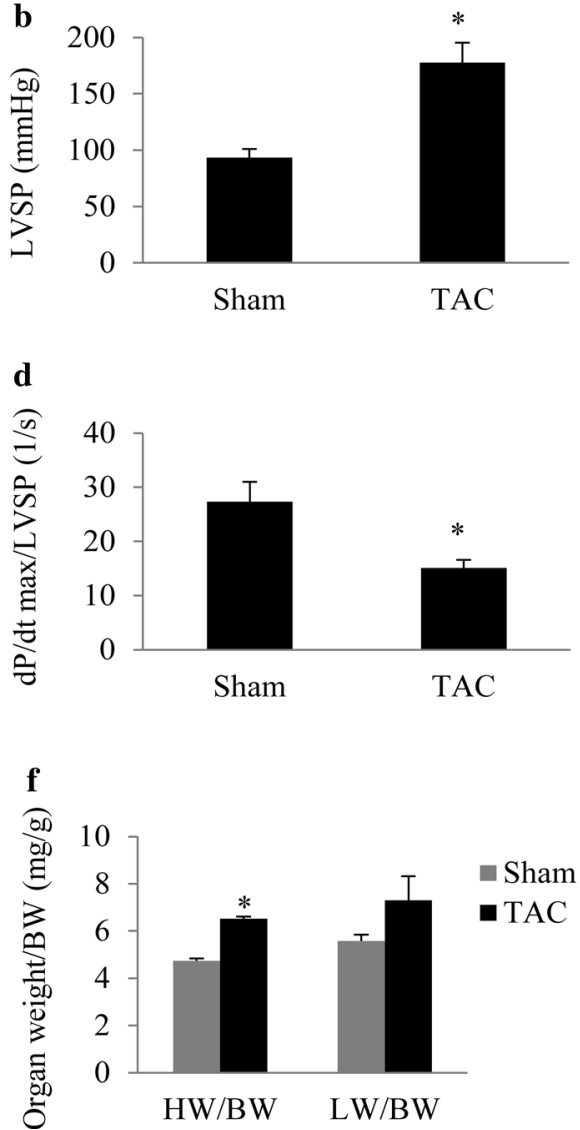

TAC
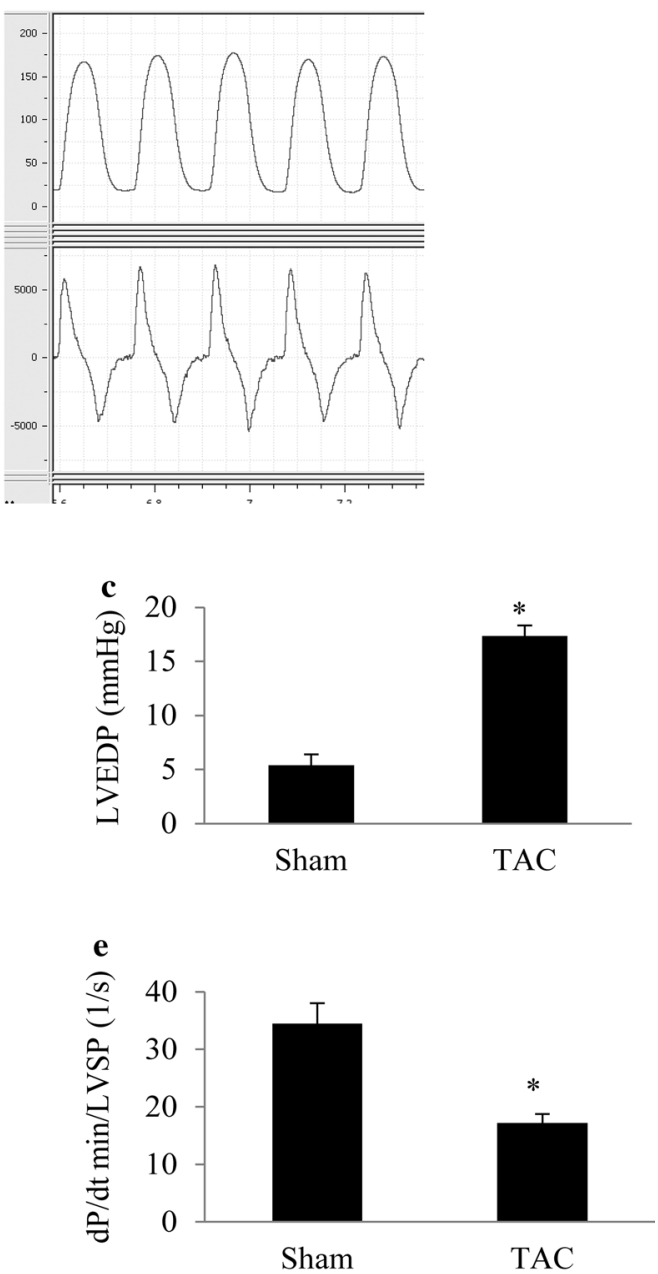

Fig. 2 Diastolic dysfunction and insulin resistance appear in mice with cardiac hypertrophy. After 2 weeks of TAC in C57 mice, invasive hemodynamics were evaluated. a Representative recordings of left ventricular pressure and the rate of change in pressure. $\mathbf{b}$ Left ventricular systolic pressure (LVSP). c Left ventricular end-diastolic pressure (LVEDP). d Maximum rate of change in left ventricular pressure (dp/dt max) corrected by LVSP. $\mathbf{e}$ Minimum rate of change in left ventricular pressure (dp/dt min) corrected by LVSP. f Heart to body weight ratio (HW/BW) and lung to body weight ratio $(\mathrm{LW} / \mathrm{BW}) .{ }^{*} P<0.05$ versus the sham group, $\mathrm{n}=9$ in each group 


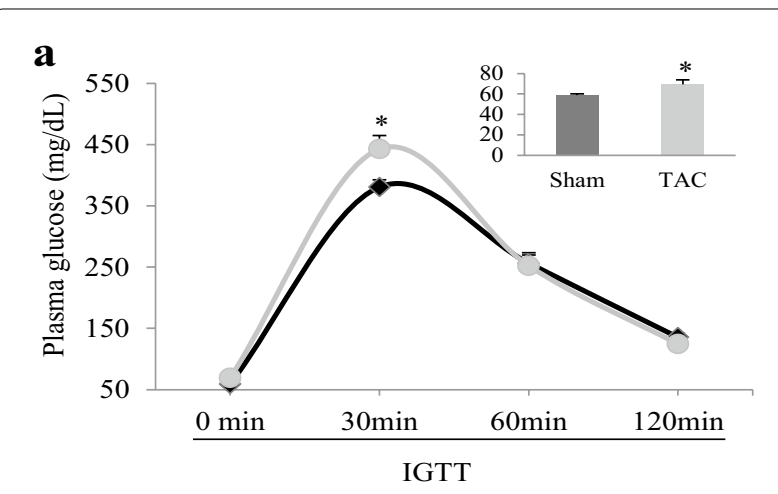

b
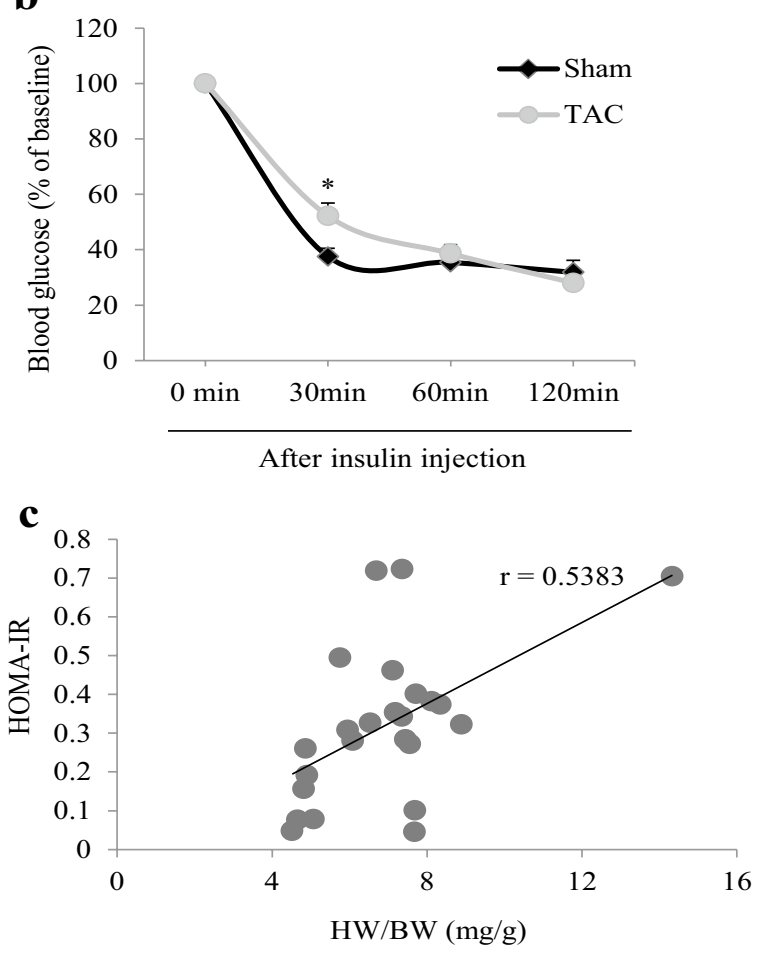

Fig. 3 Insulin resistance appears in mice with TAC for 2 weeks. a Plasma glucose concentrations in response to an intraperitoneal glucose tolerance test (IGTT, after fasting for $14 \mathrm{~h}$, glucose $2 \mathrm{~g} / \mathrm{kg}$, ip). The insert shows fasting glucose levels. $\mathbf{b}$ Time course of plasma glucose concentrations after insulin injection. c Linear correlation between HOMA-IR and heart weight to body weight ratio (HW/BW) in the TAC and sham mice groups. ${ }^{*} P<0.05$ versus the corresponding sham group, $n=16$ and 12 in the sham and TAC groups, respectively, (panels $\mathbf{a}, \mathbf{b}) ; n=24$ for panel $\mathbf{c}$

\section{Discussion}

LV diastolic dysfunction can be induced in patients with hypertension, myocardial hypertrophy, or DM. These disorders may also co-exist in patients with metabolism syndrome, which is likely to accelerate diastolic dysfunction. Our previous studies demonstrated that better glucose control with voglibose, an alpha-glycosidase inhibitor, or vildagliptin, a dipeptidyl-peptidase IV inhibitor, improves heart failure in mice with $\operatorname{TAC}[3,25]$. In patients with acute myocardial infarction, acute hyperglycemic stress at admission predicts poor long-term prognosis [12, 26], but the mechanisms are not clearly understood. Diastolic dysfunction is a critical prognostic factor for cardiovascular and some non-cardiovascular diseases [5, 9]. However, the effect of acute hyperglycemia on the hypertrophied heart with preexistent diastolic dysfunction and the mechanisms involved remain unclear. In this study, we found that acute hyperglycemia suppressed diastolic function in the hypertrophied heart, downregulated PGC-1 $\alpha$, a master regulator of mitochondrial biogenesis and function, and inhibited autophagic flux (see a summary in Fig. 8).

Acute hyperglycemia is a transient hyperglycemia referred to as stress-induced hyperglycemia. Acute hyperglycemia is commonly observed on admission and during hospitalization for cardiovascular diseases, and non-cardiovascular diseases, such as traumatic injury, burns and surgical intervention. This condition is associated with an increase in morbidity and mortality compared with hospitalized patients with normal glucose levels [27]. A recent report by Baranyai et al. [28] demonstrated that cardioprotection exerted by remote ischemic preconditioning can be abolished by acute hyperglycemia. Mebazaa et al. [29] reported that hyperglycemia is a prognostic predictor for mortality of patients with acute heart failure. They found a $9 \%$ increase in the risk of 30-day mortality for every $1 \mathrm{mmol} / \mathrm{L}$ increase in blood glucose concentration in patients with acute heart failure.

With regard to the effect of chronic hyperglycemia on the heart, Rubin et al. [30] reported that chronic hyperglycemia contributes to subclinical myocardial damage in persons without clinically evident coronary heart disease. This clinical finding is in agreement with our results that STZ-induced chronic hyperglycemia suppressed LV diastolic function in mice without preexistent cardiovascular disease.

Pre-clinical diastolic dysfunction is prevalent and will progress to symptomatic heart failure [31]. In patients with DM or hypertension, diastolic dysfunction is a risk of progression to heart failure and death $[32,33]$. In agreement with previous studies $[3,34]$, in our study, we found that fasting glucose and glucose tolerance were impaired in hypertensive mice induced by TAC. This situation may be one of the reasons for diastolic dysfunction. Catena et al. [35] reported that impaired fasting glucose and glucose tolerance were associated with more prominent diastolic impairment in uncomplicated hypertensive patients, which is in consist with findings in our study.

Mitochondrial dysfunction of cardiomyocytes has been implicated in heart failure of diverse etiologies. PGC- $1 \alpha$ 
a

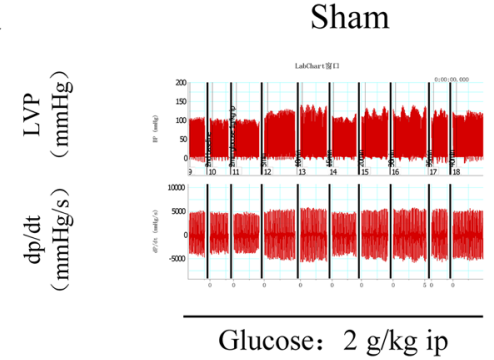

b
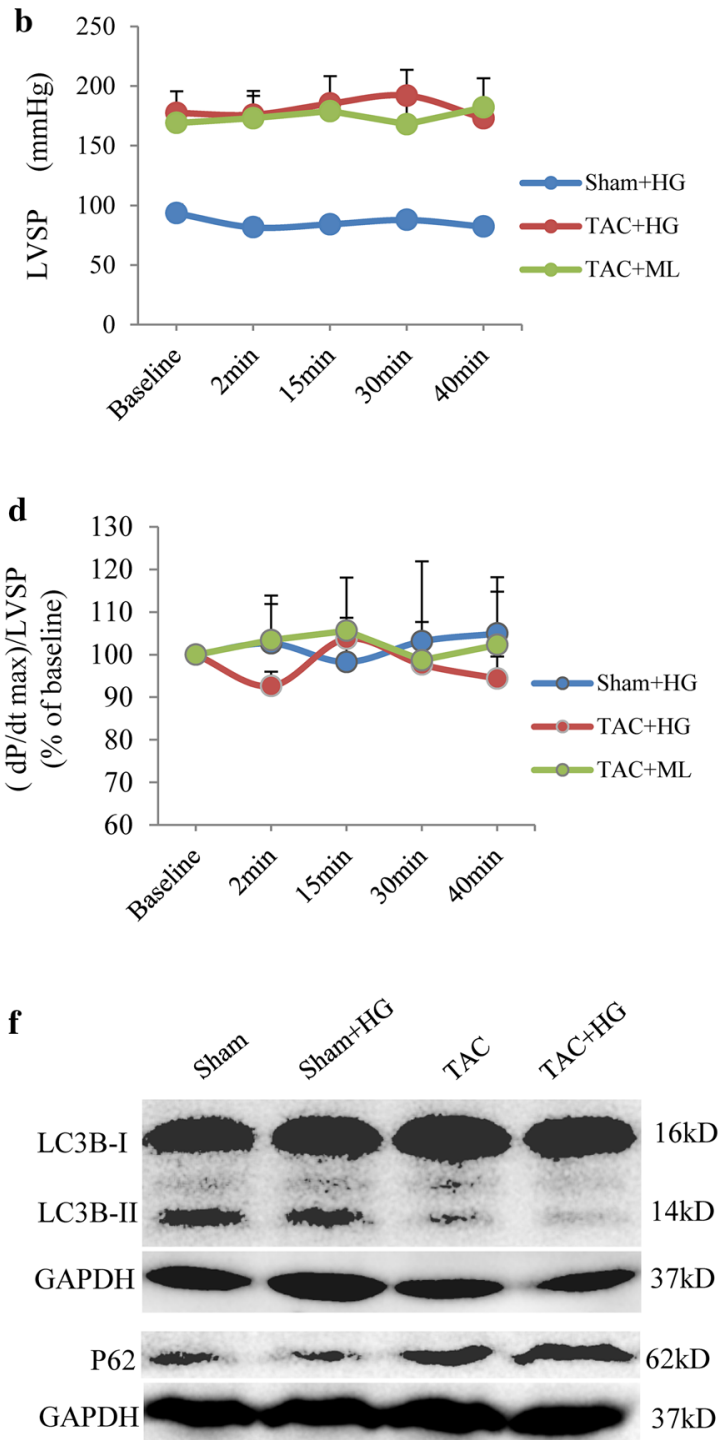

$6 \mathrm{kD}$
TAC

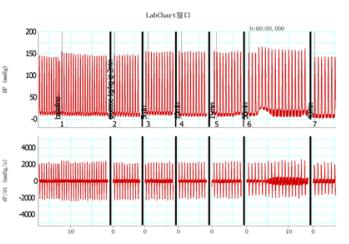

Glucose: $2 \mathrm{~g} / \mathrm{kg}$ ip
TAC

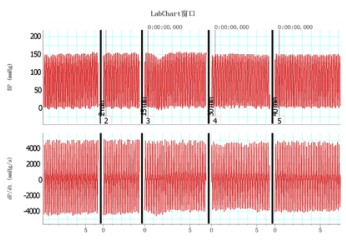

Mannitol: $2 \mathrm{~g} / \mathrm{kg}$ ip
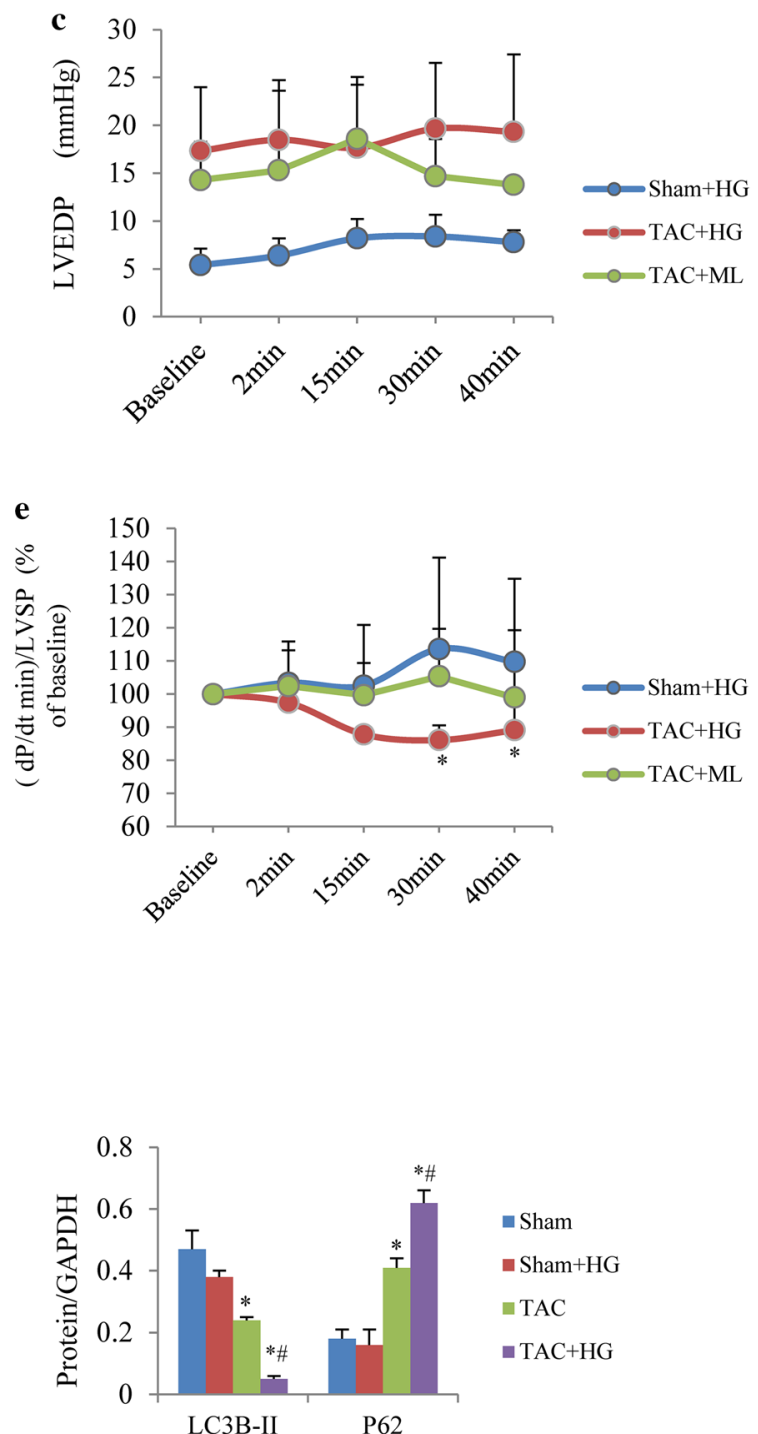

Fig. 4 Acute hyperglycemic stress suppresses diastolic function in mice with TAC for 2 weeks. a Representative time course recordings of left ventricular pressure (LVP) and the rate of rise and fall rate of $L V(d p / d t)$. b Time course of left ventricular systolic pressure (LVSP). c Time course of left ventricular end-diastolic pressure (LVEDP). d Time course of corrected dp/dt max in response to glucose overload (2 g/kg, ip). e Time course of corrected $\mathrm{dp} / \mathrm{dt}$ min in response to glucose overload. ${ }^{*} P<0.05 \mathrm{vs}$. the corresponding time point in the sham group, $\mathrm{n}=5$ per group. $\mathbf{f}$ Western blot analysis of $L C 3 B-I I$ and P62. ${ }^{*} P<0.05$ vs. sham group; ${ }^{*} P<0.05$ vs. TAC group, $\mathrm{n}=5$ per group 
$\mathbf{a}$

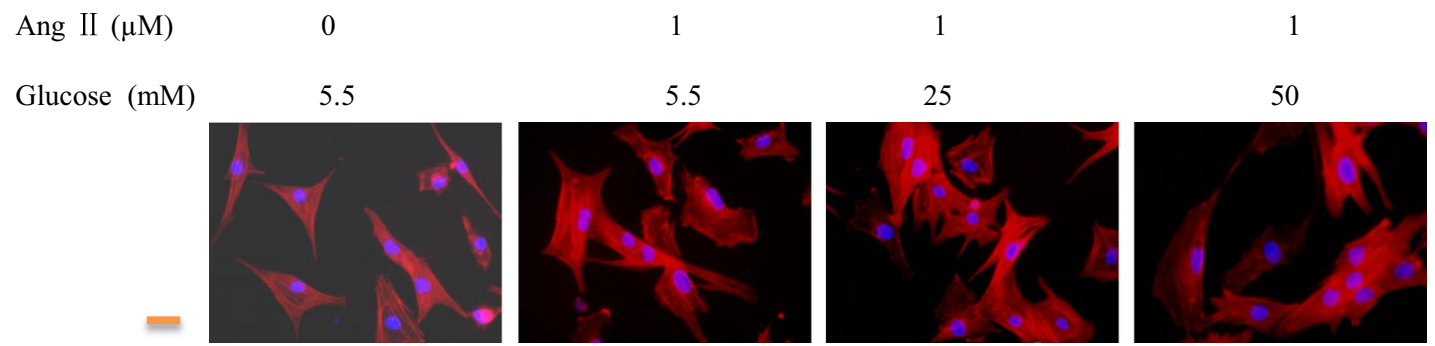

b

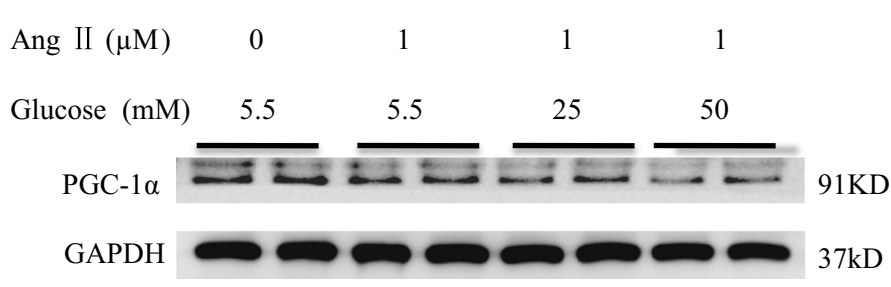

d

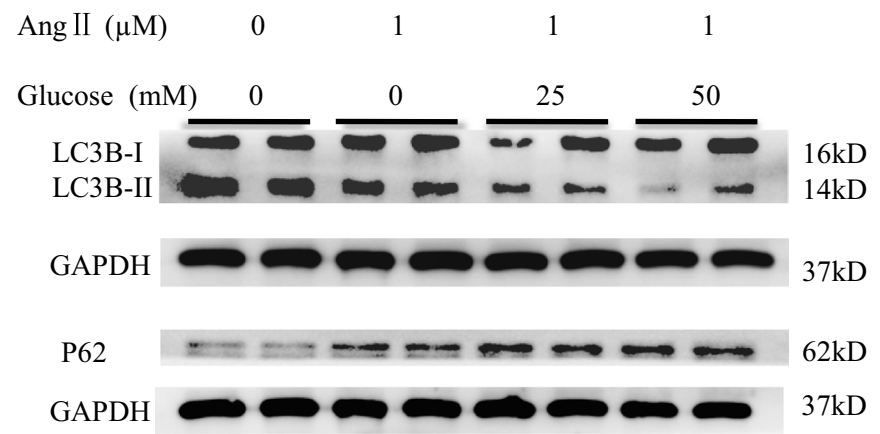

f

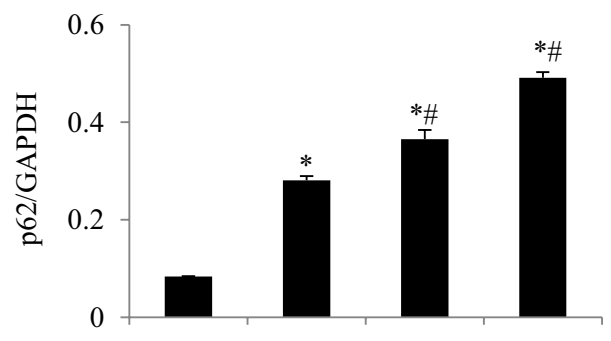

Ang II $(\mu \mathrm{M}) \quad 0 \quad 1 \quad 1 \quad 1$

Glucose (mM) $\quad 5.5 \quad 5.5 \quad 25 \quad 50$

Fig. 5 High glucose levels downregulate PGC-1a and inhibit autophagic flux. a Representative pictures of cultured neonatal rat cardiomyocytes (NRCs) stained with $\beta$-actin plus DAPI staining of the nucleus in response to angiotensin II stimulation with/without high glucose stimulation. Western blot analysis of PGC-1 a (b, c), LC3B-II (d, e), and P62 (d, f) expression in cultured NRCs. ${ }^{*} P<0.05$ vs. control group, ${ }^{\#} P<0.05$ vs. angiotensin II group. Each experiment was repeated four times 

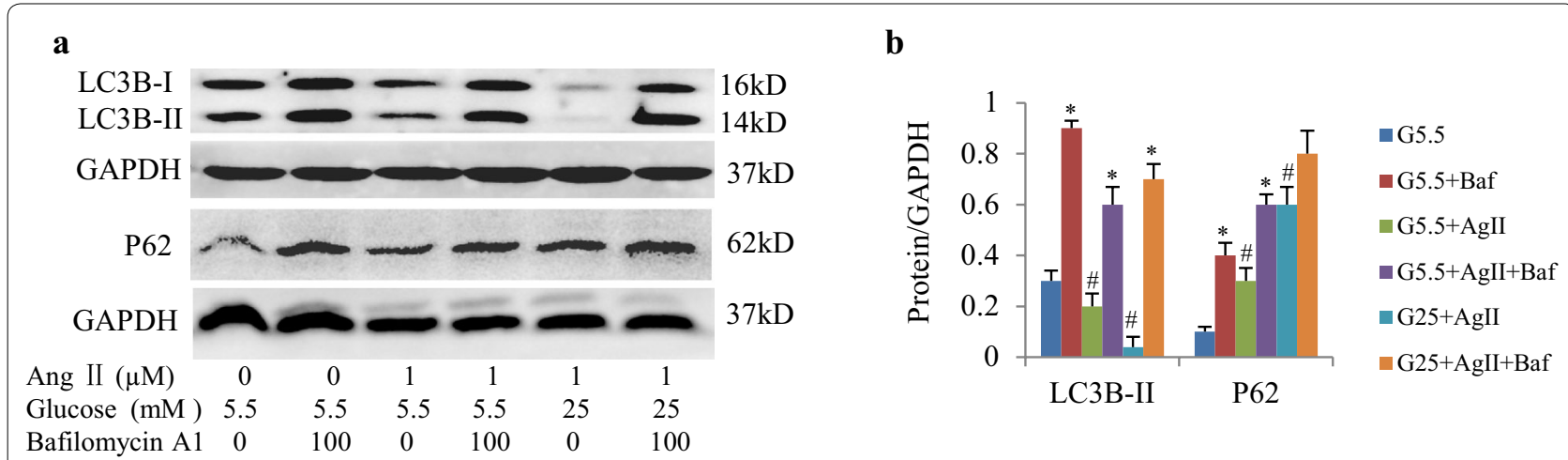

(nM)

\section{c} Ang II $(\mu \mathrm{M})$
Glucose $(\mathrm{mM})$ Baf A1 (nM) $\begin{array}{lll}0 & 0 & 1 \\ 5.5 & 5.5 & 5.5 \\ 0 & 100 & 0\end{array}$
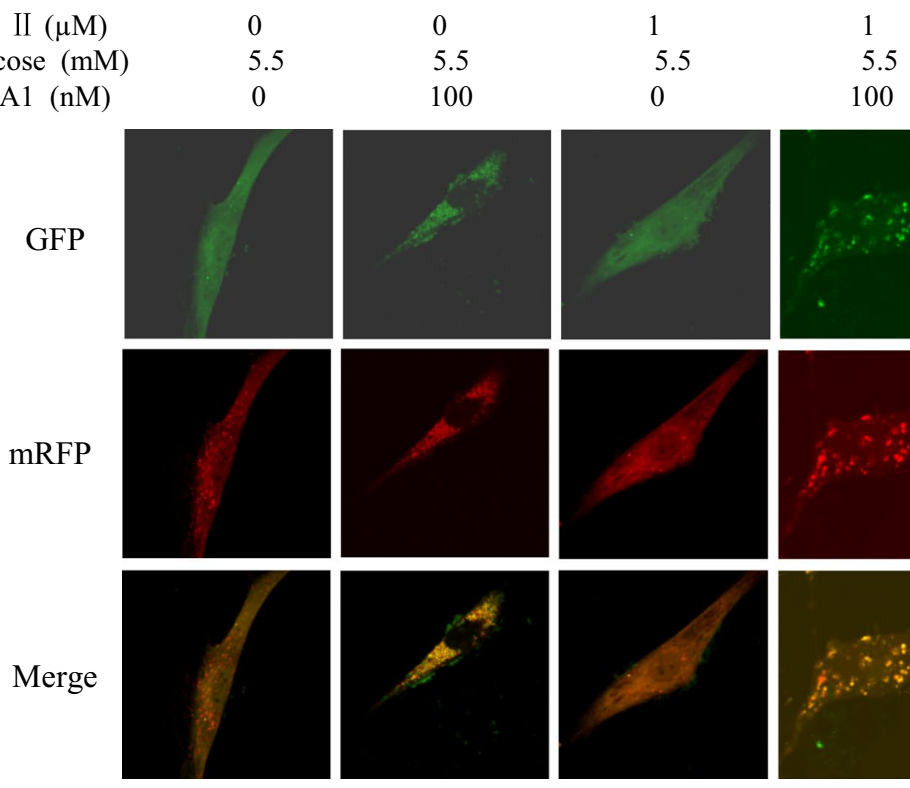
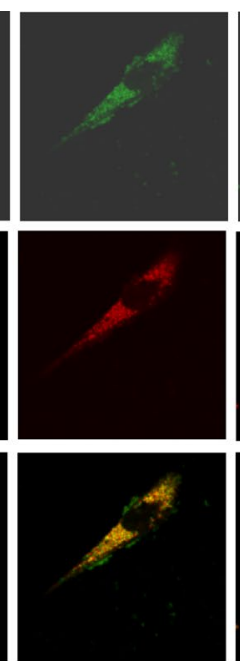
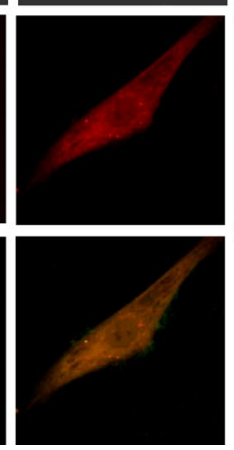
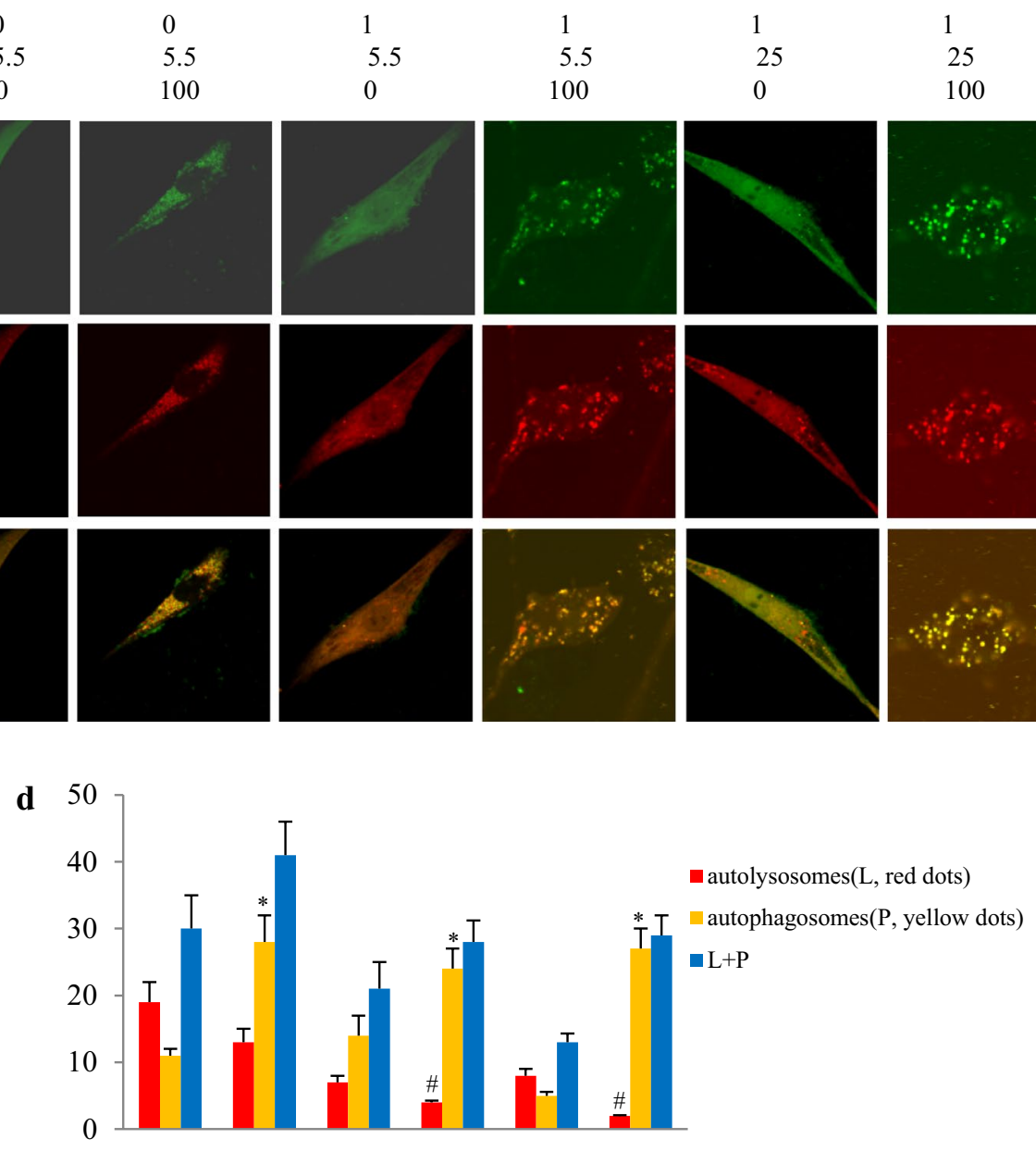

$\begin{array}{lllllll}\text { Ang II }(\mu \mathrm{M}) & 0 & 0 & 1 & 1 & 1 & 1 \\ \text { Glucose }(\mathrm{mM}) & 5.5 & 5.5 & 5.5 & 5.5 & 25 & 25 \\ \text { Bafilomycin A1 } & 0 & 100 & 0 & 100 & 0 & 100 \\ (\mathrm{nM}) & & & & & & \end{array}$

Fig. 6 High glucose levels inhibit autophagic flux in cultured neonatal rat cardiomyocytes. a Western blot images of LC3B-II and P62 in cultured neonatal rat cardiomyocytes (NRCs) in the presence of bafilomycin A1. b Semi-quantitation of LC3B-II and P62 expression levels. c Representative immunofluorescent NRCs expressing mRFP-GFP-LC3. d Semi-quantitation of autophagosomes (yellow) and autolysosomes (red). ${ }^{*} P<0.05$ vs. the autophagosomes in the corresponding group without bafilomycin $\mathrm{A} 1$ treatment; ${ }^{\#} P<0.05 \mathrm{vs}$. the autolysosomes in the corresponding group without bafilomycin A1 treatment. Experiments were repeated four times. G5.5, glucose $5.5 \mathrm{mmol} / \mathrm{L} ; \mathrm{G} 25$, glucose $25 \mathrm{mmol} / \mathrm{L}$; Ang II, angiotensin II; Baf, bafilomycin A1 


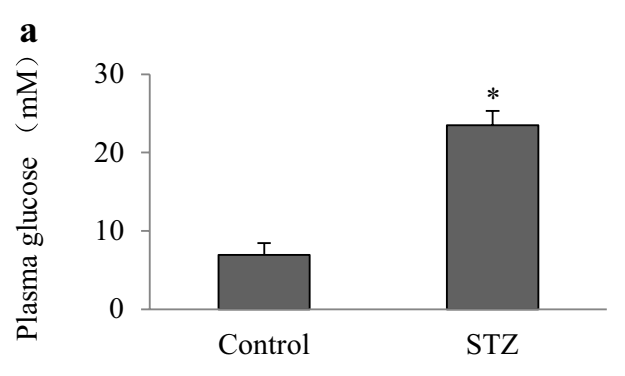

b

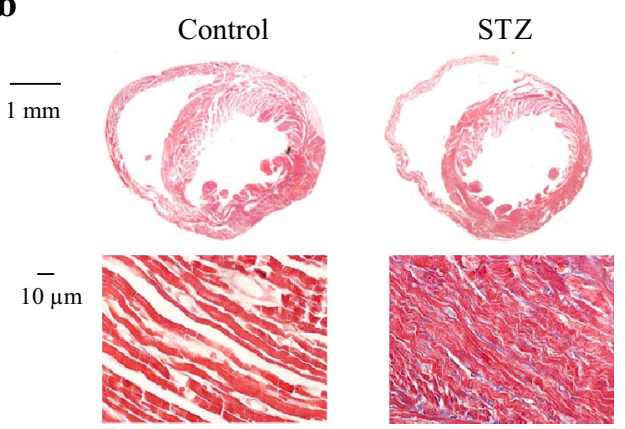

c

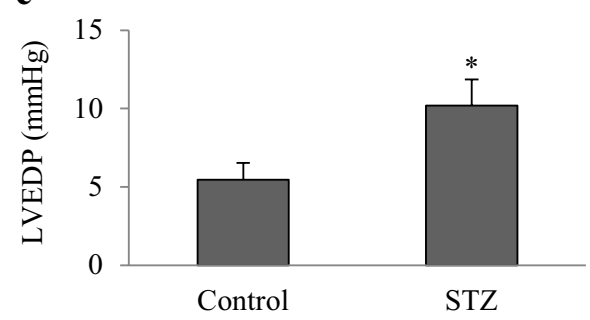

e

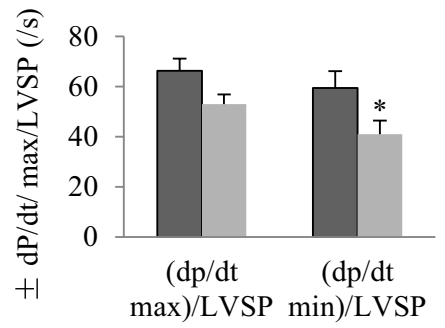

g
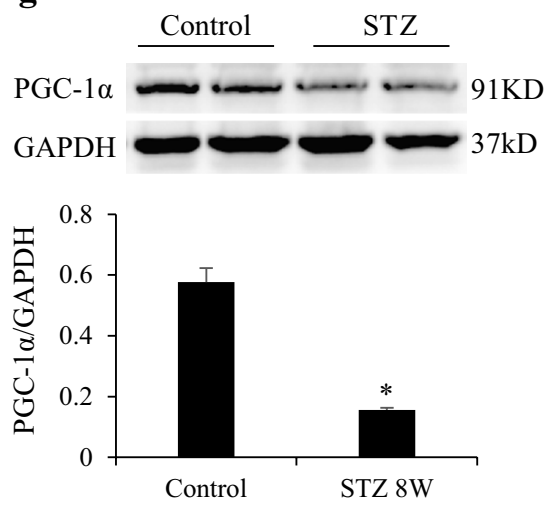

d

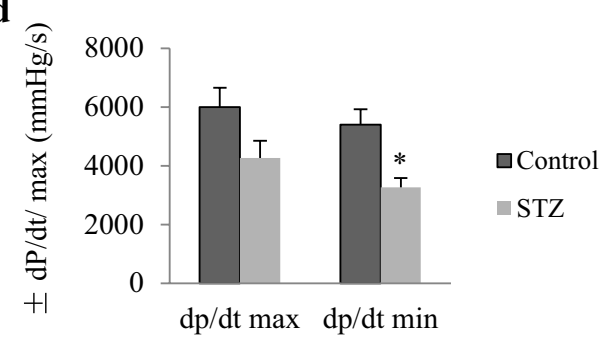

f

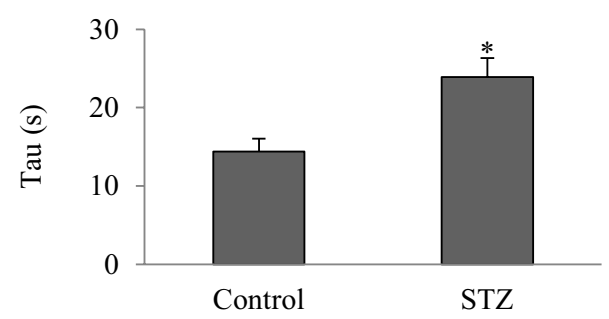

h

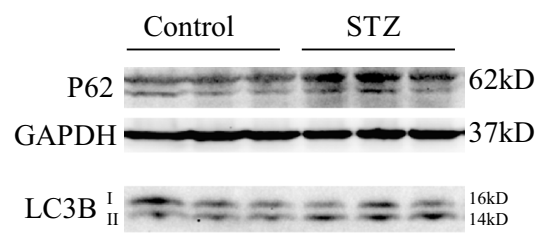

GAPDH $-37 \mathrm{kD}$

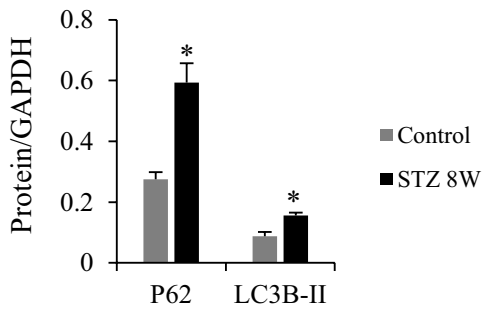

Fig. 7 Chronic hyperglycemia levels induce LV diastolic dysfunction and inhibit autophagic flux in mice at 6 weeks after induction of type 1 DM. a Plasma glucose concentrations. b Representative images of H\&E (top) and Masson stained (bottom) myocardial tissue. Scale bar $=10 \mu \mathrm{m}$. $\mathbf{c}$ Left ventricular end-diastolic pressure (LVEDP). d Maximum of change in left ventricular pressure (dp/dt max). e Minimum rate of change in left ventricular pressure (dp/dt min). f Exponential time constant of relaxation ( $\mathrm{\tau}$ ). $\mathbf{g}, \mathbf{h}$ Western blot analysis of PGC-1a, LC3B-II, and P62 expression in myocardial tissues. ${ }^{*} P<0.05$ vs. the sham group, $n=5$ per group 


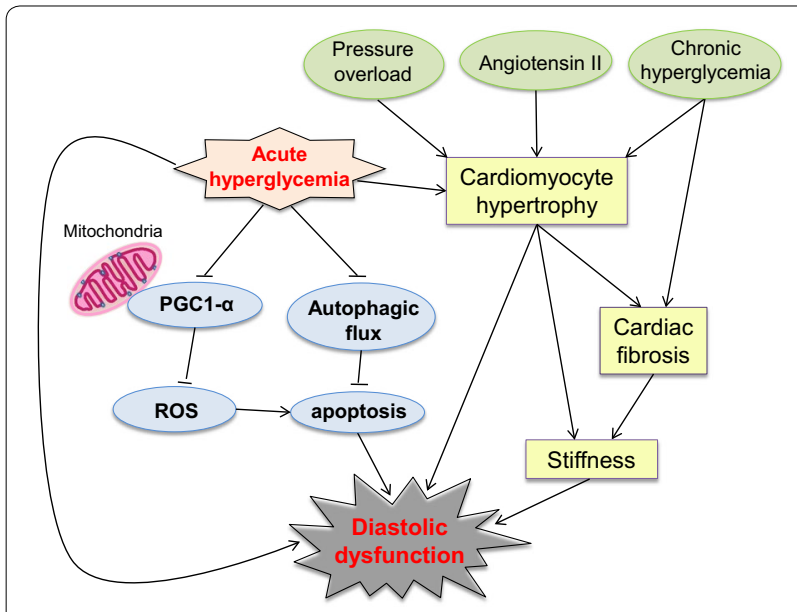

Fig. 8 Proposed hyperglycemia-mediated diastolic dysfunction signaling pathway. The solid and dotted arrows indicate evidence from our study and that from previous literature, respectively. $R O S$ reactive oxygen species; uparrow activation and; $\perp$ inhibition

is a master regulator of mitochondrial biogenesis and breathing, and downregulation or loss of PGC- $1 \alpha$ is detrimental for heart failure [36, 37]. Hyperglycemiainduced reactive oxygen species in mitochondria play a critical role in the development of complications from diabetes. Overexpression of PGC- $1 \alpha$ completely blocks hyperglycemia-induced production of mitochondrial reactive oxygen species and promotion of mitochondrial biogenesis [38]. Based on these lines of evidence, our study suggests high glucose-downregulated PGC- $1 \alpha$ contributes to diastolic dysfunction. Recent studies have shown that stimulating mitochondrial function or control of glucose with voglibose or sitagliptin improves diastolic dysfunction $[39,40]$.

Diastolic dysfunction exists in the hypertrophied heart. Autophagy is diminished in response to pressure overload or $\beta$-adrenergic stimulation, although protein turnover is increased during hypertrophy [41, 42]. Wang et al. [43] reported that low concentrations of angiotensin II induce autophagy while high concentrations diminish autophagy in cultured cardiomyocytes, which is in agreement with our results. Appropriated levels of autophagic flux are thought to maintain cellular homeostasis and cell survival, which are beneficial for heart failure $[44,45]$. Numerous studies have demonstrated that autophagy is impaired in the heart under DM [45], which is also in agreement with our findings. Zhang et al. [46] recently reported that an increase in autophagy prevents cardiac fibrosis and inflammation in type $1 \mathrm{DM}$ mice. Another study showed that caloric restriction improves diastolic dysfunction in diabetic rat hearts by enhancing autophagy [47]. In our study, we observed that acute stimulation with high glucose levels rapidly downregulated LC3B-II and upregulated P62. This finding suggested inhibition of an autophagy by reducing formation of autophagosomes. Zhang et al. [48] reported that induction of autophagosome can be as fast as $15 \mathrm{~min}$ after treatment of retinal pigment epithelial cells with the drug N-retinyl-N-retinylidene ethanolamine.

In contrast to acute hyperglycemia, chronic hyperglycemia increased myocardial LC3B-II level. This situation could be due to long-term inhibition of autophagic flux as shown by upregulation of P62. Kanamori et al. [49] reported diastolic impairment and in increase of LC3 II and P62 in mice with type $1 \mathrm{DM}$, which is consistent with our findings. However, the differences between acute and chronic hyperglycemia on autophagic activity need to be further clarified. Taken together, our findings suggest that reactivation of autophagy is likely to improve diastolic dysfunction induced by myocardial hypertrophy and DM.

\section{Conclusion}

Acute hyperglycemia suppresses diastolic function, damages mitochondrial energy signaling, and inhibits autophagic flux in prohypertrophic factor-stimulated cardiomyocytes. Our findings suggest that preventing acute hyperglycemia is of clinical importance for avoiding deterioration of diastolic dysfunction in patients with LV hypertrophy. Modulation of autophagy may be a novel strategy for improving diastolic dysfunction induced by myocardial hypertrophy and DM.

\section{Abbreviations}

LV: left ventricular; TAC: transverse aortic constriction; PGC)-1a: peroxisome proliferator-activated receptor- $\gamma$ coactivator 1a; DM: diabetes mellitus; LC3B-II: light chain 3 beta-II; P62: ubiquitin-binding autophagy receptor; STZ: streptozocin; LVSP: LV systolic pressure; LVEDP: LV end diastolic pressure; HOMA-IR: homeostasis model assessment for insulin resistance.

\section{Authors' contributions}

All of the authors have made an important contribution to the study and are thoroughly familiar with the original data. The contribution of each author is as follows: (1) conception and design (YL, KC, MK), (2) conducting the experiment (YL, JX, HH, YZ, KC) (3) analysis and interpretation of data (YL, XH, SC, $W L, J B, J X, H H, Y Z, Z C, H L, K C, M K)$, (4) drafting of the manuscript or revising it critically for important intellectual content (YL, KC, YZ); (5) All authors read and approved the final manuscript.

\section{Author details}

1 State Key Laboratory of Organ Failure Research, Department of Cardiology, Nanfang Hospital, Southern Medical University, 1838 Guangzhou avenue north, Guangzhou 510515, China. ${ }^{2}$ Department of Oncology, Nanfang Hospital, Southern Medical University, Guangzhou 510515, Guangdong, China. ${ }^{3}$ Cardiovascular Division of the Department of Medicine, National Cerebral and Cardiovascular Center, Osaka, Japan.

\section{Acknowledgements}

This study was supported by Grants from the National Natural Science Foundation of China (No. 81170146, No.81570464), and the Provincial Natural Science Foundation of Guangdong (2014A030313342, 2015A030313301, 2015A030313298) 


\section{Competing financial interests}

The authors declare that they have no competing financial interests.

\section{Availability of data and material}

Yes.

\section{Consent for publication}

If the manuscript is accepted, we approve of it for publication in Cardiovascular Diabetology.

\section{Ethics approval and consent to participate}

Approval for this study was granted by our university ethics review board. All procedures were performed in accordance with our Institutional Guidelines for Animal Research (Nanfang Hospital, Southern Medical University) and complied with the Guide for the Care and Use of Laboratory Animals published by the US National Institutes of Health (NIH Publication No. 85-23, revised 1996).

Received: 15 June 2016 Accepted: 13 September 2016

Published online: 22 September 2016

\section{References}

1. Palmieri V, Russo C, Bella JN. Treatment of isolated left ventricular diastolic dysfunction in hypertension: reaching blood pressure target matters. Hypertension. 2010;55(2):224-5.

2. Wei X, Wu B, Zhao J, Zeng Z, Xuan W, Cao S, Huang X, Asakura M, Xu D, Bin J, et al. Myocardial hypertrophic preconditioning attenuates cardiomyocyte hypertrophy and slows progression to heart failure through upregulation of S100A8/A9. Circulation. 2015;131(17):1506-17 (Discussion 1517)

3. Liao Y, Takashima S, Zhao H, Asano Y, Shintani Y, Minamino T, Kim J, Fujita M, Hori M, Kitakaze M. Control of plasma glucose with alpha-glucosidase inhibitor attenuates oxidative stress and slows the progression of heart failure in mice. Cardiovasc Res. 2006;70(1):107-16.

4. Bugyei-Twum A, Advani A, Advani SL, Zhang Y, Thai K, Kelly DJ, Connelly KA. High glucose induces Smad activation via the transcriptional coregulator p300 and contributes to cardiac fibrosis and hypertrophy. Cardiovasc Diabetol. 2014;13:89

5. Ren X, Ristow B, Na B, Ali S, Schiller NB, Whooley MA. Prevalence and prognosis of asymptomatic left ventricular diastolic dysfunction in ambulatory patients with coronary heart disease. Am J Cardiol. 2007;99(12):1643-7.

6. Khan JN, Wilmot EG, Leggate M, Singh A, Yates T, Nimmo M, Khunti K, Horsfield MA, Biglands J, Clarysse P, et al. Subclinical diastolic dysfunction in young adults with Type 2 diabetes mellitus: a multiparametric contrast-enhanced cardiovascular magnetic resonance pilot study assessing potential mechanisms. Eur Heart J Cardiovasc Imaging. 2014;15(11):1263-9.

7. Milwidsky A, Maor E, Kivity S, Berkovitch A, Zekry SB, Tenenbaum A, Fisman EZ, Erez A, Segev S, Sidi Y, et al. Impaired fasting glucose and left ventricular diastolic dysfunction in middle-age adults: a retrospective cross-sectional analysis of 2971 subjects. Cardiovasc Diabetol. 2015;14:119.

8. Di Bello V, Talini E, Dell'Omo G, Giannini C, Delle Donne MG, Canale ML, Nardi C, Palagi C, Dini FL, Penno G, et al. Early left ventricular mechanics abnormalities in prehypertension: a two-dimensional strain echocardiography study. Am J Hypertens. 2010;23(4):405-12.

9. Landesberg G, Gilon D, Meroz Y, Georgieva M, Levin PD, Goodman S, Avidan A, Beeri R, Weissman C, Jaffe AS, et al. Diastolic dysfunction and mortality in severe sepsis and septic shock. Eur Heart J. 2012;33(7):895-903.

10. Nadkarni N, Bhasin DK, Rana SS, Bahl A, Sinha SK, Rao C, Talwar KK. Diastolic dysfunction, prolonged QTc interval and pericardial effusion as predictors of mortality in acute pancreatitis. J Gastroenterol Hepatol. 2012;27(10):1576-80.

11. von Bibra H, von St John Sutton M. Diastolic dysfunction in diabetes and the metabolic syndrome: promising potential for diagnosis and prognosis. Diabetologia. 2010;53(6):1033-45.
12. Ukena C, Dobre D, Mahfoud F, Kindermann I, Lamiral Z, Tala S, Rossignol P, Turgonyi E, Pitt B, Bohm M, et al. Hypo- and hyperglycemia predict outcome in patients with left ventricular dysfunction after acute myocardial infarction: data from EPHESUS. J Card Fail. 2012;18(6):439-45.

13. Kobayashi S, Xu X, Chen K, Liang Q. Suppression of autophagy is protective in high glucose-induced cardiomyocyte injury. Autophagy. 2012:8(4):577-92.

14. Oka T, Hikoso S, Yamaguchi O, Taneike M, Takeda T, Tamai T, Oyabu J, Murakawa T, Nakayama H, Nishida K, et al. Mitochondrial DNA that escapes from autophagy causes inflammation and heart failure. Nature. 2012:485(7397):251-5.

15. Thomas RL, Roberts DJ, Kubli DA, Lee Y, Quinsay MN, Owens JB, Fischer KM, Sussman MA, Miyamoto S, Gustafsson AB. Loss of MCL-1 leads to impaired autophagy and rapid development of heart failure. Genes Dev. 2013;27(12):1365-77.

16. Su M, Wang J, Wang C, Wang X, Dong W, Qiu W, Wang Y, Zhao X, Zou $Y$, Song $L$, et al. MicroRNA-221 inhibits autophagy and promotes heart failure by modulating the p27/CDK2/mTOR axis. Cell Death Differ. 2015;22(6):986-99.

17. Rawat DK, Alzoubi A, Gupte R, Chettimada S, Watanabe M, Kahn AG, Okada T, McMurtry IF, Gupte SA. Increased reactive oxygen species, metabolic maladaptation, and autophagy contribute to pulmonary arterial hypertension-induced ventricular hypertrophy and diastolic heart failure. Hypertension. 2014;64(6):1266-74.

18. Besseiche A, Riveline JP, Gautier JF, Breant B, Blondeau B. Metabolic roles of PGC-1alpha and its implications for type 2 diabetes. Diabetes Metab. 2015;41(5):347-57.

19. Vainshtein A, Tryon LD, Pauly M, Hood DA. Role of PGC-1alpha during acute exercise-induced autophagy and mitophagy in skeletal muscle. Am J Physiol Cell Physiol. 2015;308(9):C710-9.

20. Shi L, Zhang T, Zhou Y, Zeng X, Ran L, Zhang Q, Zhu J, Mi M. Dihydromyricetin improves skeletal muscle insulin sensitivity by inducing autophagy via the AMPK-PGC-1alpha-Sirt3 signaling pathway. Endocrine. 2015;50(2):378-89.

21. Liao Y, Asakura M, Takashima S, Ogai A, Asano Y, Asanuma H, Minamino T, Tomoike H, Hori M, Kitakaze M. Benidipine a long-acting calcium channel blocker, inhibits cardiac remodeling in pressure-overloaded mice. Cardiovasc Res. 2005;65(4):879-88.

22. Saha JK, Xia J, Grondin JM, Engle SK, Jakubowski JA. Acute hyperglycemia induced by ketamine/xylazine anesthesia in rats: mechanisms and implications for preclinical models. Exp Biol Med (Maywood). 2005:230(10):777-84

23. Xuan W, Wu B, Chen C, Chen B, Zhang W, Xu D, Bin J, Liao Y. Resveratrol improves myocardial ischemia and ischemic heart failure in mice by antagonizing the detrimental effects of fractalkine. Crit Care Med. 2012;40(11):3026-33.

24. Klionsky DJ, Abdelmohsen K, Abe A, Abedin MJ, Abeliovich H, Acevedo Arozena A, Adachi H, Adams CM, Adams PD, Adeli K, et al. Guidelines for the use and interpretation of assays for monitoring autophagy (3rd edition). Autophagy. 2016;12(1):1-222.

25. Takahashi A, Asakura M, Ito S, Min KD, Shindo K, Yan Y, Liao Y, Yamazaki S, Sanada S, Asano Y, et al. Dipeptidyl-peptidase IV inhibition improves pathophysiology of heart failure and increases survival rate in pressure-overloaded mice. Am J Physiol Heart Circ Physiol. 2013;304(10):H1361-9.

26. Capes SE, Hunt D, Malmberg K, Gerstein HC. Stress hyperglycaemia and increased risk of death after myocardial infarction in patients with and without diabetes: a systematic overview. Lancet. 2000;355(9206):773-8.

27. Harp JB, Yancopoulos GD, Gromada J. Glucagon orchestrates stressinduced hyperglycemia. Diabetes Obes Metab. 2016.

28. Baranyai T, Nagy CT, Koncsos G, Onodi Z, Karolyi-Szabo M, Makkos A, Varga ZV, Ferdinandy P, Giricz Z. Acute hyperglycemia abolishes cardioprotection by remote ischemic perconditioning. Cardiovasc Diabetol. 2015;14:151.

29. Mebazaa A, Gayat E, Lassus J, Meas T, Mueller C, Maggioni A, Peacock F, Spinar J, Harjola VP, van Kimmenade R, et al. Association between elevated blood glucose and outcome in acute heart failure: results from an international observational cohort. J Am Coll Cardiol. 2013;61(8):820-9.

30. Rubin J, Matsushita K, Ballantyne CM, Hoogeveen R, Coresh J, Selvin E. Chronic hyperglycemia and subclinical myocardial injury. J Am Coll Cardiol. 2012;59(5):484-9. 
31. Wan SH, Vogel MW, Chen HH. Pre-clinical diastolic dysfunction. J Am Coll Cardiol. 2014;63(5):407-16.

32. Brzyzkiewicz H, Konduracka E, Gajos G, Janion M. Incidence of chronic heart failure with preserved left ventricular ejection fraction in patients with hypertension and isolated mild diastolic dysfunction. Pol Arch Med Wewn. 2016;126(1-2):12-8.

33. From AM, Scott CG, Chen HH. The development of heart failure in patients with diabetes mellitus and pre-clinical diastolic dysfunction a population-based study. J Am Coll Cardiol. 2010;55(4):300-5.

34. Zhang L, Jaswal JS, Ussher JR, Sankaralingam S, Wagg C, Zaugg M, Lopaschuk GD. Cardiac insulin-resistance and decreased mitochondrial energy production precede the development of systolic heart failure after pressure-overload hypertrophy. Circ Heart Fail. 2013;6(5):1039-48.

35. Catena C, Colussi G, Martinis F, Pezzutto F, Sechi LA. Plasma glucose levels and left ventricular diastolic function in nondiabetic hypertensive patients. Am J Hypertens. 2013;26(11):1353-61.

36. Yang Y, Zhang H, Li X, Yang T, Jiang Q. Effects of PPARalpha/PGC-1alpha on the myocardial energy metabolism during heart failure in the doxorubicin induced dilated cardiomyopathy in mice. Int J Clin Exp Med. 2014;7(9):2435-42.

37. Arany Z, Novikov M, Chin S, Ma Y, Rosenzweig A, Spiegelman BM. Transverse aortic constriction leads to accelerated heart failure in mice lacking PPAR-gamma coactivator 1alpha. Proc Natl Acad Sci U S A. 2006;103(26):10086-91.

38. Kukidome D, Nishikawa T, Sonoda K, Imoto K, Fujisawa K, Yano M, Motoshima H, Taguchi T, Matsumura T, Araki E. Activation of AMPactivated protein kinase reduces hyperglycemia-induced mitochondrial reactive oxygen species production and promotes mitochondrial biogenesis in human umbilical vein endothelial cells. Diabetes. 2006;55(1):120-7.

39. Chen Y, Zhang Z, Hu F, Yang W, Yuan J, Cui J, Hao S, Hu J, Zhou Y, Qiao S. 17beta-estradiol prevents cardiac diastolic dysfunction by stimulating mitochondrial function: a preclinical study in a mouse model of a human hypertrophic cardiomyopathy mutation. J Steroid Biochem Mol Biol. 2015;147:92-102.
40. Oe H, Nakamura K, Kihara H, Shimada K, Fukuda S, Takagi T, Miyoshi T, Hirata K, Yoshikawa J, Ito H, et al. Comparison of effects of sitagliptin and voglibose on left ventricular diastolic dysfunction in patients with type 2 diabetes: results of the 3D trial. Cardiovasc Diabetol. 2015;14:83-96.

41. Nakai A, Yamaguchi O, Takeda T, Higuchi Y, Hikoso S, Taniike M, Omiya S, Mizote I, Matsumura Y, Asahi M, et al. The role of autophagy in cardiomyocytes in the basal state and in response to hemodynamic stress. Nat Med. 2007;13(5):619-24.

42. Pfeifer U, Fohr J, Wilhelm W, Dammrich J. Short-term inhibition of cardiac cellular autophagy by isoproterenol. J Mol Cell Cardiol. 1987;19(12):1179-84.

43. Wang X, Dai Y, Ding Z, Khaidakov M, Mercanti F, Mehta JL. Regulation of autophagy and apoptosis in response to angiotensin II in $\mathrm{HL}-1$ cardiomyocytes. Biochem Biophys Res Commun. 2013;440(4):696-700.

44. Nishida K, Otsu K. Autophagy during cardiac remodeling. J Mol Cell Cardiol. 2015.

45. Sciarretta S, Boppana VS, Umapathi M, Frati G, Sadoshima J. Boosting autophagy in the diabetic heart: a translational perspective. Cardiovasc Diagn Ther. 2015;5(5):394-402.

46. Zhang J, Cheng Y, Gu J, Wang S, Zhou S, Wang Y, Tan Y, Feng W, Fu Y, Mellen N, et al. Fenofibrate increases cardiac autophagy via FGF21/SIRT1 and prevents fibrosis and inflammation in the hearts of Type 1 diabetic mice. Clin Sci (Lond). 2016;130(8):625-41.

47. Makino N, Oyama J, Maeda T, Koyanagi M, Higuchi Y, Tsuchida K. Calorie restriction increases telomerase activity, enhances autophagy, and improves diastolic dysfunction in diabetic rat hearts. Mol Cell Biochem. 2015;403(1-2):1-11.

48. Zhang J, Bai Y, Huang L, Qi Y, Zhang Q, Li S, Wu Y, Li X. Protective effect of autophagy on human retinal pigment epithelial cells against lipofuscin fluorophore A2E: implications for age-related macular degeneration. Cell Death Dis. 2015;6:e1972.

49. Kanamori H, Takemura G, Goto K, Tsujimoto A, Mikami A, Ogino A, Watanabe T, Morishita K, Okada H, Kawasaki M, et al. Autophagic adaptations in diabetic cardiomyopathy differ between type 1 and type 2 diabetes. Autophagy. 2015;11(7):1146-60.

\section{Submit your next manuscript to BioMed Central and we will help you at every step:}

- We accept pre-submission inquiries

- Our selector tool helps you to find the most relevant journal

- We provide round the clock customer support

- Convenient online submission

- Thorough peer review

- Inclusion in PubMed and all major indexing services

- Maximum visibility for your research

Submit your manuscript at www.biomedcentral.com/submit
() Biomed Central 